\title{
RANCANG BANGUN SISTEM INFORMASI PERSEDIAAN ATK PADA PD. BANK PERKREDITAN RAKYAT KERTA RAHARJA KAB. TANGERANG
}

\author{
Janu Ilham Saputro ${ }^{1}$ \\ Cici Alviona Roza ${ }^{2}$ \\ Marini Ekawati ${ }^{3}$ \\ Dosen STMIK Raharja ${ }^{1}$ \\ AMIK Raharja Informatika Jurusan Komputerisasi Akuntansi ${ }^{2,3}$ \\ Jl. Jenderal Sudirman No.40, Modernland, Tangerang ${ }^{1,2,3}$ \\ E-mail:janu@raharja.info, ${ }^{1}$ cici.alviona@raharja.info, ${ }^{2}$ marini@raharja.info ${ }^{3}$
}

\begin{abstract}
ABSTRAK
Perusahan Daerah Bank Perkreditan Rakyat ( PD.BPR ) Kerta Raharja merupakan Perusahaan Daerah milik Pemerintah Kabupaten Tangerang bersama-sama Pemerintah Provinsi Banten, Provinsi Jawa Barat dan PT Bank Jabar Banten, sesuai dengan Peraturan Daerah Kabupaten Tangerang, nomor 6 tahun 2007, tanggal 6 Juni 2007, Tentang Pembentukan Perusahaan Daerah Bank Perkreditan Rakyat Kerta Raharja Kabupaten Tangerang dan telah mendapat izin operasional dari Gubernur Bank Indonesia nomor.10/3/Kep.GBI/DpG/2008, tanggal 22 Januari 2008. Sistem Informasi stok barang yang berjalan saat ini masih manual sehingga memperlambat proses pendataan. Hal tersebut mengakibatkan proses kegiatan menjadi tidak efektif karena membutuhkan waktu yang lama. Metode penelitian yang digunakan adalah metode mengumpulan data, metode analisis dan metode perancangan. Metode pengumpulan data dilakukan dengan mengadakan observasi langsung di perusahaan, melakukan dokumentasi dengan mempelajari dokumen-dokumen yang ada, riset terhadap masalah, wawancara kepada pihak terkait di perusahaan dan studi pustaka dari beberapa penelitian sebelumnya. Metode Analisa sistem menggunakan UML (Unified Modelling Language). Metode perancangan menggunakan model yang berorientasi objek dengan menggunakan UML (Unified Modeling Language) dan menggunakan bahasa pemrogramman PHP (PHP Hypertext Preprocessor). Dengan tahapan metode-metode tersebut penulis menemukan masalah-masalah dalam rancang bangun sistem informasi persediaan ATK yang sedang berjalan dan menemukan solusi yang terbaik bagi perusahaan. Adapun hasil penelitian ini adalah suatu sistem persediaan ATK untuk membantu perusahaan dalam mengelola sistem informasi persediaan barang yang lebih efektif dan efisien. Kesimpulan dari diterapkannya sistem informasi persediaan barang yang baru pada perusahaan adalah menjadikan proses pengarsipan data-data persediaan barang menjadi lebih rapi dan pembuatan laporan persediaan barang menjadi cepat, tepat waktu dan lebih informatif.
\end{abstract}

Kata Kunci: Sistem Informasi, persediaan barang ATK

\section{ABSTRACT}

Company Regional Rural Banks (PD.BPR) Kerta Raharja is a Local Company owned Tangerang Regency Government together Government Banten, West Java and PT Bank Jabar Banten, in accordance with Regulation Tangerang District, No. 6 of 2007, June 6 2007, on the Establishment of Regional Rural Bank Company Kerta Prog Tangerang District and has received an operating permit from the Governor of Bank Indonesia nomor.10 / 3 / KEP.GBI / DpG / 2008, dated 22 January 2008. Information Systems running inventory is still thus slowing manual data collection process. This resulted in the process of becoming ineffective because it requires a lot of time. The method used is a method of gathering data, and analysis methods. Methods of data collection is done by conducting direct observation in the company, documentation by studying existing documents, research the issue, interviews with stakeholders in the company and literature of several previous studies. Methods of system analysis using UML (Unified Modeling Language). By stage of these methods the authors found problems in the information system of performance appraisal is running and find the best solution for the company. The benefits of this research is to assist companies in building analysis 
system inventory information more effectively and efficiently. The conclusion from this study is the application of systems analysis application inventory information that is new to the company, makes the process of archiving data in a neat inventory and inventory report generation to be fast, timely and more informative.

Keywords: [Analysis, Information Systems, Inventory of goods.]

\section{PENDAHULUAN}

Dalam perkembangan teknologi informasi yang kian pesat, informasi yang akurat berorientasi pada komputerisasi sangatlah dibutuhkan. Komputer merupakan alat untuk mengolah data dengan cepat, tepat, dan akurat menurut prosedur telah ditentukan sehingga teknologi komputer saat ini menjadi suatu kebutuhan yang sudah sangat mendasar dan tidak dapat dipisahkan.

Sistem komputerisasi merupakan penunjang yang sangat berarti dalam aktivitas kerja suatu instansi dalam menghemat waktu dan tenaga. Hal ini diyakini dapat mempermudah proses pengolahan data dan dapat mengurangi adanya kesalahan saat pengolahan data.

Untuk mendukung sistem pengelolaan data yang baik, dibutuhkan suatu sistem untuk mengolah sistem stok barang dengan baik. Sistem stok barang yang baik akan memberikan kemudahan dalam penyajian informasi yang dibutuhkan.

Sistem persediaan alat tulis kantor pada BPR KR kab. Tangerang yang berjalaan saat ini menggunakan aplikasi Ms. Excel. Oleh karena itu sering terjadi kesalahan dan kesulitan dalam penyajian data yang dapat merugikan pihak-pihak tertentu.

Dalam sistem pendataan persediaan alat tulis kantor seperti ini, terdapat kesulitan karena harus menghitung persediaan barang secara manual sehingga sangat rentan salah dan tidak efisien waktu. Permasalahan seperti ini tidak dapat dilakukan terus menerus, oleh karena itu perlu adanya sistem pendataan persediaan barang secara komputerisasi, agar masalah yang terjadi dapat diatasi.

\section{LANDASAN TEORI}

\section{A. Definisi Sistem}

"Menurut Yakub (2012:1), "Sistem adalah suatu jaringan kerja dari prosedur-prosedur yang berhubungan, terkumpul bersama-sama untuk melakukan suatu kegiatan atau tujuan tertentu".

"Menurut Sutabri (2012:10), berpendapat bahwa "Suatu sistem dapat diartikan sebagai suatu kumpulan atau himpunan dari unsur, komponen, atau variabel yang terorganisir, saling berinteraksi, saling tergantung satu sama lain, dan terpadu".

\section{Definisi Sistem Informasi}

Sistem informasi terdapatbeberapa pandangan menurut para ahli, antara lain sebagai berikut:

a. Menurut Tata Sutabri (2012:46) [2], berpendapat bahwa "Sistem informasi adalah suatu sistem didalam suatu organisasi yang mempertemukan kebutuhan pengolahan transaksi harian yang mendukung fungsi operasi organisasi yang bersifat manajerial dengan kegiatan strategi dari suatu organisasi untuk dapat menyediakan kepada pihak luar tertentu dengan laporan-laporan yang diperlukan”. 
b. Menurut Sutarman (2012:13) [4], berpendapat bahwa "Sistem informasi adalah sistem dapat didefinisikan dengan mengumpulkan, memperoses, menyimpan, menganalisis, menyebarkan informasi untuk tujuan tertentu. Seperti sistem lainnya, sebuah sistem informasi terdiri atas input (data, instruksi) dan output (laporan, kalkulasi)".

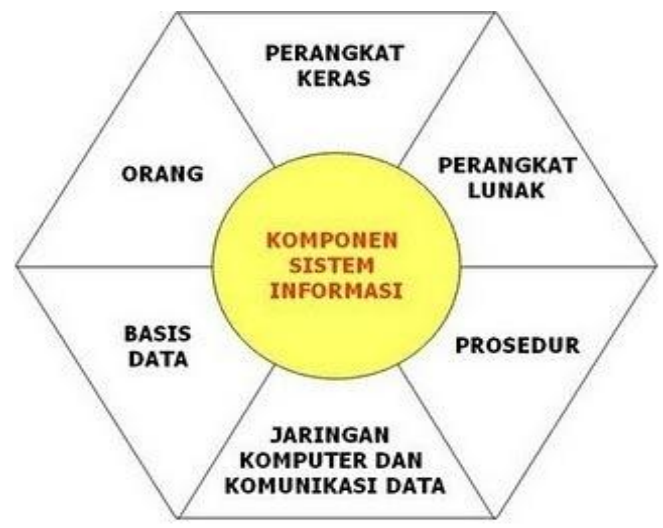

\section{Gambar 1. Komponen Sistem Informasi}

Komponenen sistem informasi :

1. Perangkat keras (hardware): mencakup peranti-peranti fisik seperti komputer dan printer.

2. Perangkat lunak (software) atau program: sekumpulan instruksi yang memungkinkan perangkat keras untuk dapat memproses data.

3. Prosedur: sekumpulan aturan yang dipakai untuk mewujudkan pemrosesan data dan pembangkitan keluaran yang dikehedaki.

4. Orang: semua pihak yang bertanggung jawab dalam pengembangan sistem informasi, pemrosesan, dan penggunaan keluaran sistem informasi.

5. Basis data (database): sekumpulan tabel, hubungan, dan lain-lain yang berkaitan dengan penyimpanan data.

6. Jaringan komputer dan komunikasi data: sistem penghubung yang memungkinkan sesumber (resources) dipakai secara bersama atau diakses oleh sejumlah pemakai.

\section{B. Definisi Persediaan}

Persediaan merupakan suatu model yang umum digunakan untuk menyelesaikan masalah yang terkait dengan usaha pengendalian bahan baku maupun barang jadi dalam suatu aktifitas perusahaan. Inventory atau persediaan adalah suatu teknik untuk manajemen material yang berkaitan dengan persediaan. Manajemen material dalam inventory dilakukan dengan beberapa input yang digunakan yaitu : permintaan yang terjadi dan biaya-biaya yang terkait dengan penyimpanan, serta biaya apabila terjadi kekurangan persediaan (short age). (Agus Ristono, $2013: 1-2$ )

\section{LITERATURE REVIEW}

1. Penelitian yang dilakukan oleh Windy Lia Safitri (2014)“Analisa Sistem Informasi Manajemen Persediaan Barang Pada CV. Samat Teknik Mandiri”. Penelitian ini dilakukan untuk merancang sistem yang sedang berjalan yaitu dari sistem manual menjadi terkomputerisasi yang berbentuk program, sehingga dapat mengakses data dan 
informasi secara cepat dalam segi pengolahan data, efisien dalam segi tenaga, akurat dalam segi informasi yang lengkap dan mempermudah dalam mengetahui jumlah persediaan barang yang tersedia dalam suatu gudang.

2. Penelitian yang dilakukan oleh Ferry Susanto (2013) berjudul "Analisa Sistem Penerimaan dan Pengeluaran Barang Berbasis Web pada PT. PANCA PRIMA EKABROTHERS". Dalam penelitian ini terdapat kesimpulan bahwa sistem penerimaan dan pengeluaran barang pada PT. PANCA PRIMA EKABROTHERS memiliki kendala didalam sistem gudang yang hanya dikerjakan dengan menggunakan excel dan pengarsipannya atidak teratur dengan baik, hal ini menyebabkan laporan yang dihasilkan memerlukan waktu yang cukup lama dan tidak akura dalam pengolahan data.

3. Penelitian yang dilakukan oleh Yulianti (2011) yang berjudul "Analisa Sistem Informasi Inventory Control di PT. Panarub Industri”. Dalam penelitian ini terdapat kesimpulan bahwa pada pengecekan barang jadi sering terjadi kesalahan dalam penginputan data yang berulang-ulang dikarenakan pengecekan yang masih manual.Agar proses pengolahan barang jadi berjalan dengan baik dan akurat, maka diperlukan perencanaan yang matang mengenai sistem informasi pengolahan data yang didukung oleh sistem yang terkomputerisasi.

4. Penelitian yang dilakukan oleh Mutia Anisa Novianti (2014) yang berjudul "Perancangan Executive Information System (EIS) Penjualan Di PT. Tirta Varia Intipratama". Sistem informasi pengolahan data penjualan di PT. Tirta Varia Intipratama yang berjalan saat ini masih menggunakan Ms. Excel sehingga proses pengolahan data penjualan berjalan lambat, belum akurat dan menghambat pihak eksekutif dalam memperoleh informasi penjualan. Dengan dirancangnya Executive Information System (EIS) Penjualan dengan pengolahan data penjualan yang ada pada database. Perancangan dimulai dari penjabaran daftar kebutuhan yang dituangkan dalam elisitasi melalui 4 (empat) tahap, dengan menggunakan teknik MDI pada tahap ke dua, teknik TOE pada tahap ke tiga. Dilanjutkan dengan pembuatan diagram UML, yang terdiri dari lima buah diagram yaitu usecase diagram, sequencediagram, activity diagram, state chart diagram, dan class diagram sebagai awal rancangan sistem yang akan dibuat, selanjutnya dibuatlah programming dengan bahasa pemrograman PHP dengan Framework CodeIgniter (CI) sesuai dengan desain prototype yang ada. XAMPPsebagai pendukung aplikasi yang digunakan sebagai web server dan juga menggunakan MySQL sebagai database yang dibangun. Sebagai media tampilan menggunakan Dreamweaver sehingga dapat menyelesaikan permasalahan yang ada.

5. Penelitian yang dilakukan oleh Ratri Ratna Dewi (2015) yang berjudul 'Perancangan Sistem Informasi Persediaan Barang Pada PT Citra Surya Selaras Berbasis Web". PT Citra Surya Selaras adalah sebuah perusahaan yang bergerak di bidang retail jam dinding, yang kegiatan utamanya adalah memberikan dan menghasilkan produk terbaik untuk para konsumen. Pada PT Citra Surya Selaras masih terdapat kekurangan dan kelemahan khususnya pada tempat penyimpanan barang yang terbatas dalam gudang sehingga penyimpanan barang tidak efektif. Didalam sistem microsoft excel yang saat ini berjalan dapat memenuhi standar mutu baik, namun masih sering kali terjadi kesalahan dalam penginputan data yang mengakibatkan selisih datapersediaan barang, serta sering terjadi hambatan saat proses kerja berlangsung karena sistem yang berjalan saat ini masih bersifat manual. Sehingga sistem yang dimaksud diharapkan dapat menghasilkan informasi yang dibutuhkan secara efisien, tepat waktu, kecepatan proses, keefektifan kerja dan informasi yang dihasilkan lebih cepat. Sistem yang berjalan saat ini ternyata masih terdapat kekurangan-kekurangan. 


\section{METODE PENELITIAN}

\section{A. Metode Analisa Data}

Metode yang dipergunakan dalam penelitian ini adalah metode deskriptif, yaitu metode penelitian dimana penulis membuat gambaran mengenai kejadian dengan tujuan untuk menggambarkan secara sistematis, aktual dan akurat mengenai fakta-fakta, sifatsifat serta hubungan antar kejadian yang diselidiki.

\section{B. Metode Pengumpulan Data}

1. Observasi

Adalah suatu metode untuk mendapatkan suatu data dengan jalan pengamatan dan untuk mencari sumber informasi dimana penulis melakukan evaluasi terhadap masalah yang ada dan melaksanakan pencatatan secara sistematis terhadap unsurunsur yang di teliti sebagai masukan dalam menyusun data untuk proses penjualan dengan cara mempelajari prosedur sistem persediaan barang pada BPR KR Kab. Tangerang.

2. Wawancara

Adalah suatu metode dimana penulis mendapatkan data dan keterangan mengenai data suatu hal dengan cara wawancara atau tanya jawab dengan pihak terkait yaitu bagian operasional dan umum.

3. Studi Kepustakaan

Penelitian yang dilakukan untuk mendpatkan informasi yang terkait dengan permasalahan yang akan diteliti, penulis mendapatkan data dengan cara membaca buku-buku yang ada dan melalui sumber-sumber dari kepustakaan yang berhubungan dengan sistem persediaan barang di BPR KR, merangkum dan mengutip data sebagai acuan penulis.

\section{PEMBAHASAN}

\section{A. Prosedur Sistem yang Berjalan}

Prosedur pemesanan persediaan barang sistem yang berjalan sebagai berikut :

1. Staf request order.

2. Kemudian Staf order ke bagian Operasional.

3. Lalu bagian Operasional mengecek stok barang yang tersedia, apabila ada stok barang bagian Operasional akan konfirmasi kepada Staf dan apabila tidak ada stok maka membuat Po kepada Supplier.

4. Kemudian Po diberikan ke Kepala bagian Administrasi Keuangan dan Umum untuk di setujui.

5. Lalu bagian Operasional mengirim Po ke Supplier melalui fax atau email.

6. Supplier menerima Po dan mengecek barang, lalu barang siap dikirim ke customer.

7. Barang diterima customer, bagian Operasional membuat laporan barang masuk, kemudian laporan diberikan kepada Kepala Bagian Administrasi Keuangan dan Umum. 


\section{B. Sistem Yang Berjalan Pada Use Case Diagram}

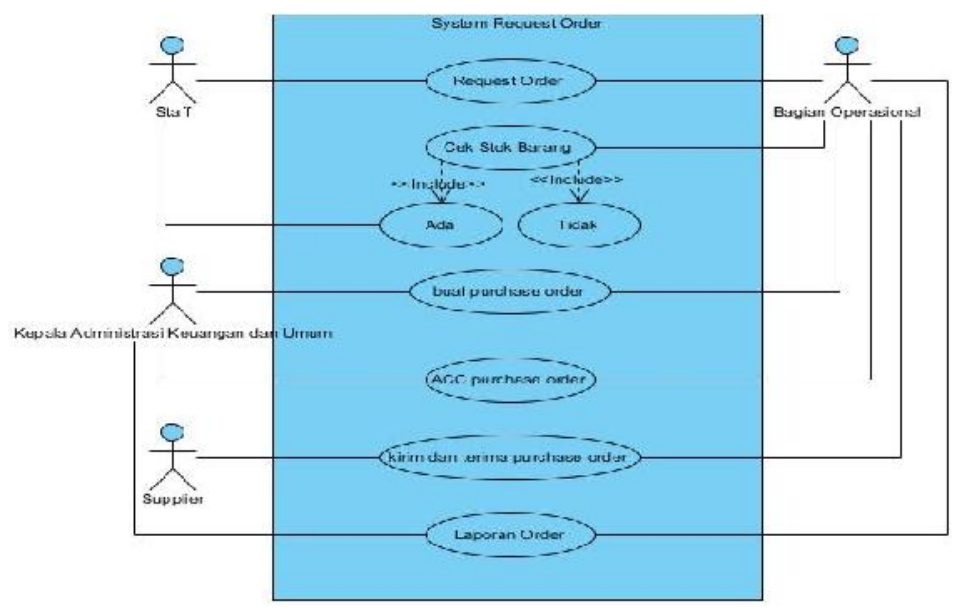

Gambar 3 Use Case Diagram

Pada gambar usecase diagram diatas terdapat 1 sistem yang mencakup seluruh kegiatan, 4 4 actor yaitu staff, bagian operasional, kepala administrasi keuangan dan umum, dan supplier.Dan ada 8 usecase yang dilakukan oleh actor.

\section{Sistem yang Berjalan pada Activity Diagram}

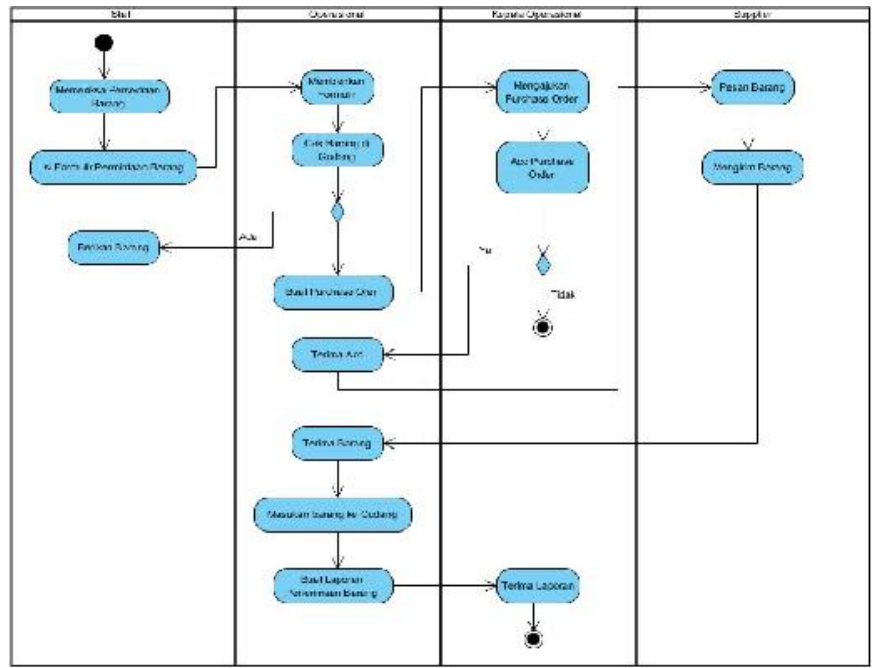

Gambar 4. Activity Diagram

Pada gambar acitivity diagram diatas terdapat 1 initial node, 4 swimlane yaitu staff operasionl, kepala operasional, dan suuplier. 15 action, 2 decision node digunakan untuk pilihan kondisi, dan 1 final node. 


\section{Sistem yang Berjalan pada Sequence Diagram}

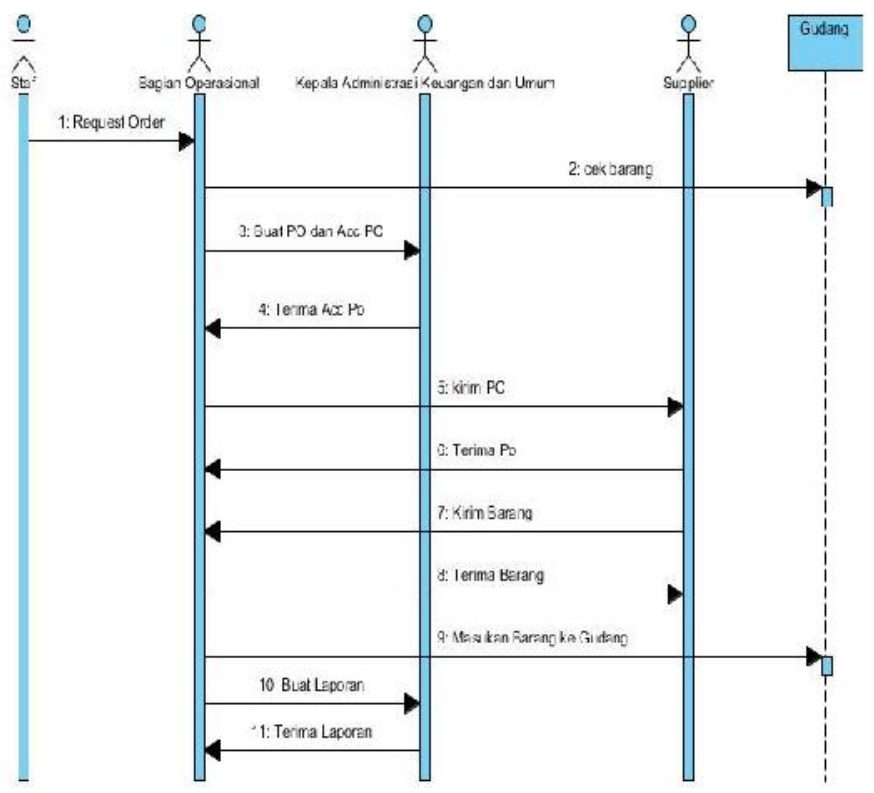

Gambar 5 Sequence Diagram

Pada gambar sequence diagram diatas terdapat 4 actor yaitu staff operasionl, kepala operasional, dan suplier. 1 lifelineyaitu gudang,dan 11 message.

\section{E. Permasalahan yang dihadapi}

Berdasarkan analisa yang dilakukan peneliti, Staf bagian opersional mengalami kesulitan mengenai informasi stok barang secara update, karena proses pencarian dan pencatatan untuk data stok menggunakan Microsoft Office Excel, admin harus mencari satu persatu untuk mengetahui data stok barang atau cara cepat dengan menggunakan Ctrl Find untuk mencari nama barang yang ditelusuri, dengan cara pencarian cepat admin harus menghafal semua nama barang dengan penulisan yang benar sesuai dengan pengetikan di Microsoft Office Excel. Pengontrolan terhadap persediaan barang kadang terjadi kelebihan pemesanan dan terjadi kekurangan barang. Persediaan barang yang kurang terintegrasi dan kesalahan input data lebih dari satu kali untuk barang sejenis menimbulkan kesalahan dalam pelaporan, yaitu kurang efektif dalam sistem pelaporan dan terjadinya laporan stok barang yang terlalu banyak (over stock) atau sebaliknya stok barang terlalu sedikit (under stock).

\section{F. Solusi yang diberikan}

Adapun alternatif pemecahan masalah sebagai berikut:

1. Mengembangkan sistem informasi persediaan barang secara terkomputerisasi agar mendapatkan informasi mengenai stok barang secara update sehingga Staf yang mengajukan permintaan barang tidak menunggu terlalu lama.

2. Membuat suatu sistem persediaan barang yang mampu melakukan pengecekan ulang secara keseluruhan.

3. Membuat suatu manajemen persediaan barang agar dapat mengelola laporan persediaan barang secara akurat dalam segi pegolahan agar tidak terjadi kesalahan pemesanan dan pengiriman barang. 


\section{G. Implementasi}

\section{a. Rancangan Aplikasi}

Dalam rancangan sistem informasi persediaan ini, penulis akan membuat website yang akan memudahkan Admin untuk mengolah data persediaan barang dan untuk mendapatkan informasinya yang mudah untuk dipahami. Atas dasar analisa kebutuhan, penulis membuat rancangan aplikasi yang sesuai dengan kebutuhan user dapat dilihat pada gambar dibawah ini.

\section{Rancangan Login Admi}

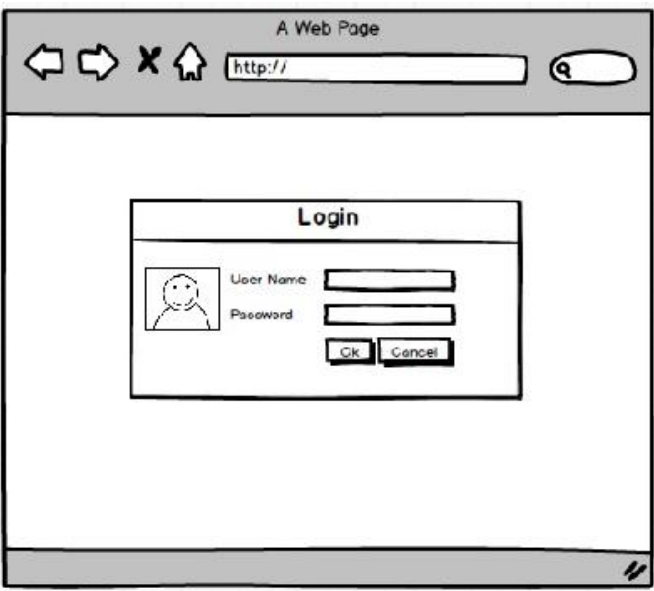

\section{Gambar 1. Rancangan Login User}

Admin login dengan menginputkan user name dan password, kemudian klik oke untuk masuk dalam aplikasi.

\section{Rancangan Home}

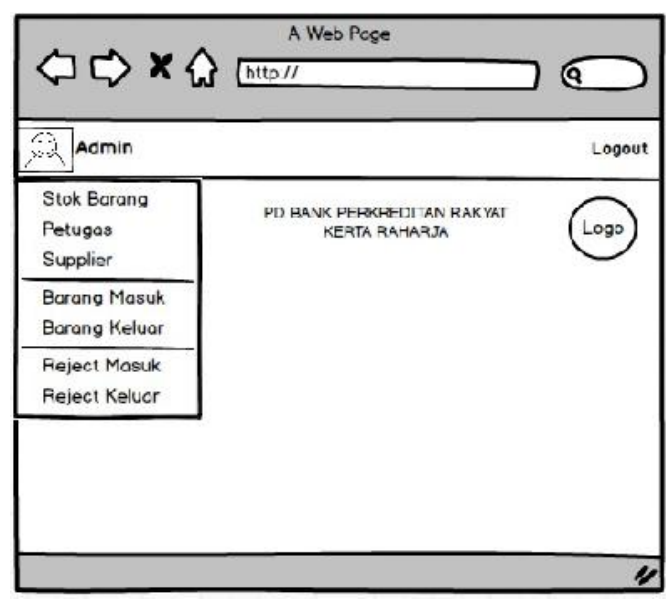

\section{Gambar 2. Rancangan Home}

Setelah user berhasil login, muncul tampilan home seperti pada gambar diatas dengan 7 menu yaitu stok barang, petugas, supplier, barang masuk, barang keluar, reject masuk dan reject keluar. 


\section{Rancangan Input Data Stok Barang}

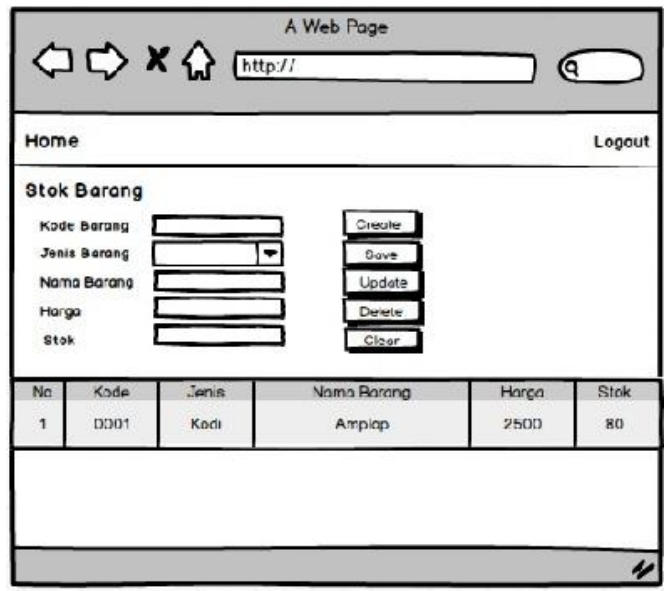

Gambar 3. Rancangan Stok Barang

Pada tampilan stok barang, user menginputkan kode barang, jenis barang, nama barang, harga, stok yang akan kita perbarui informasinya.

\section{Rancangan Input Data Petugas}

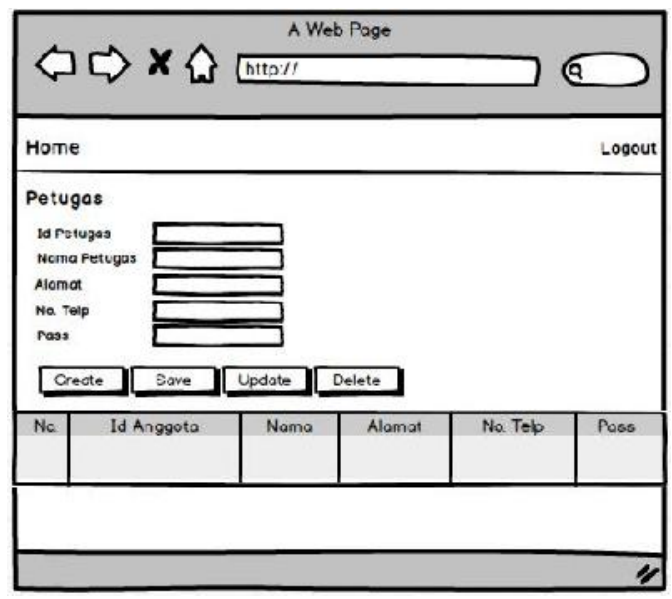

Gambar 4. Rancangan Petugas

Pada tampilan petugas, user menginputkan id petugas, nama petugas, alamat, no. telp, dan password. 


\section{Rancangan Input Data Supplier}

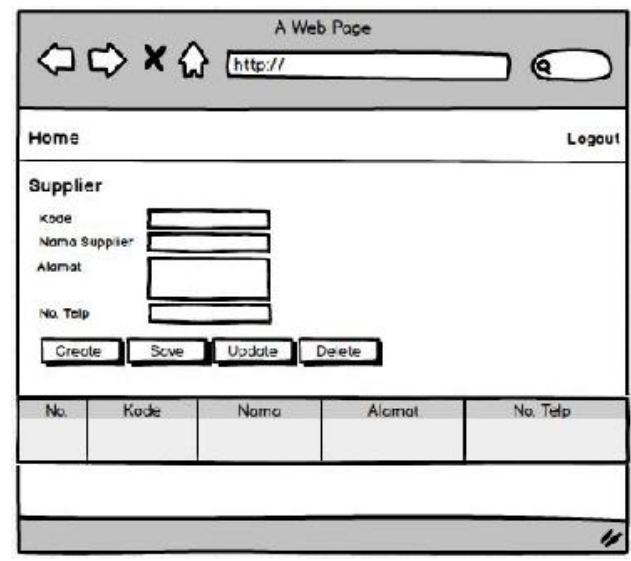

Gambar 5. Rancangan Supplier

Pada tampilan supplier, user menginputkan kode supplier, nama supplier, alamat, dan no. telp.

\section{Rancangaan Input Barang Masuk}

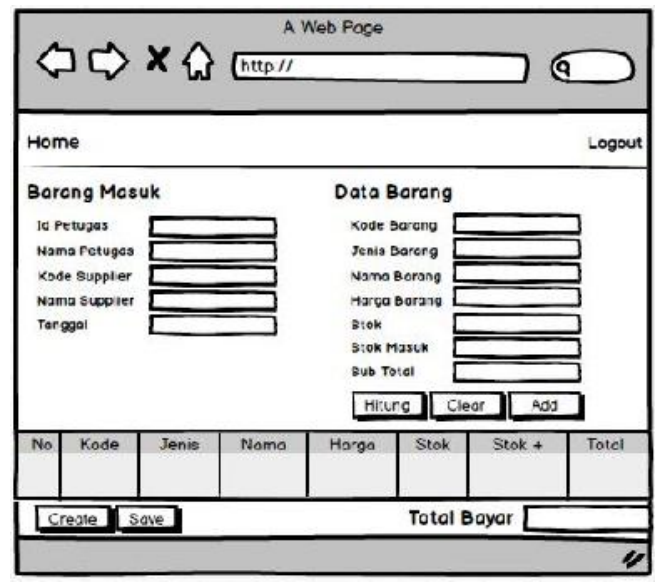

\section{Gambar 6. Rancangan Barang Masuk}

Pada tampilan barang masuk, user menginputkan id petugas, nama petugas, kode supplier, nama supplier, tanggal, dan menginputkan data barang berupa kode barang, jenis barang, nama barang, harga barang, stock, stock masuk, dan sub total. 


\section{Rancangan Input Data Barang Keluar}

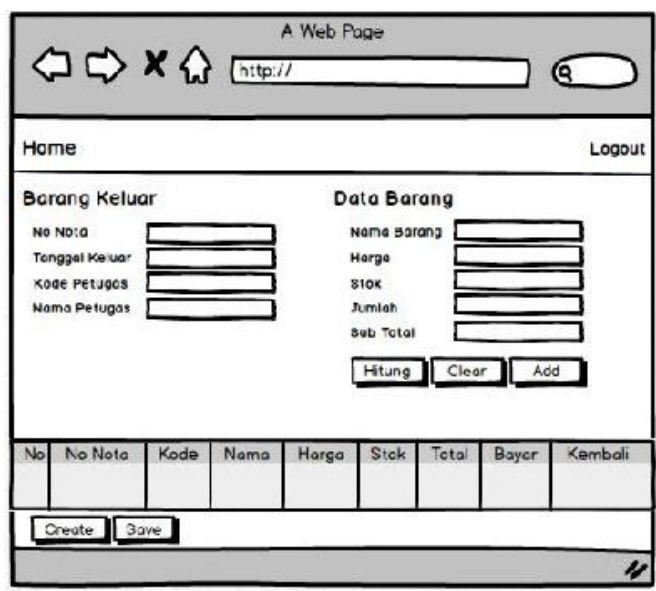

\section{Gambar 7. Rancangan Barang Keluar}

Pada tampilan barang keluar, user menginputkan no nota, tanggal keluar, kode petugas, nama petugas, dan menginputkan data barang yang keluar berupa nama barang, harga, stok, jumlah, dan sub total.

\section{Rancangan Input Data Reject Masuk}

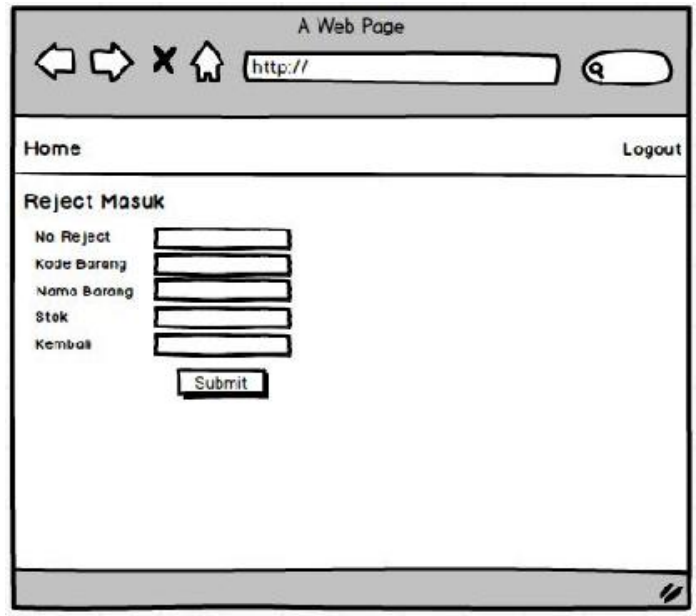

\section{Gambar 8. Rancangan Reject Masuk}

Pada tampilan reject masuk, user menginputkan no reject, kode barang, nama barang, stok, dan kembali. 


\section{Rancangan Input Data Reject Keluar}

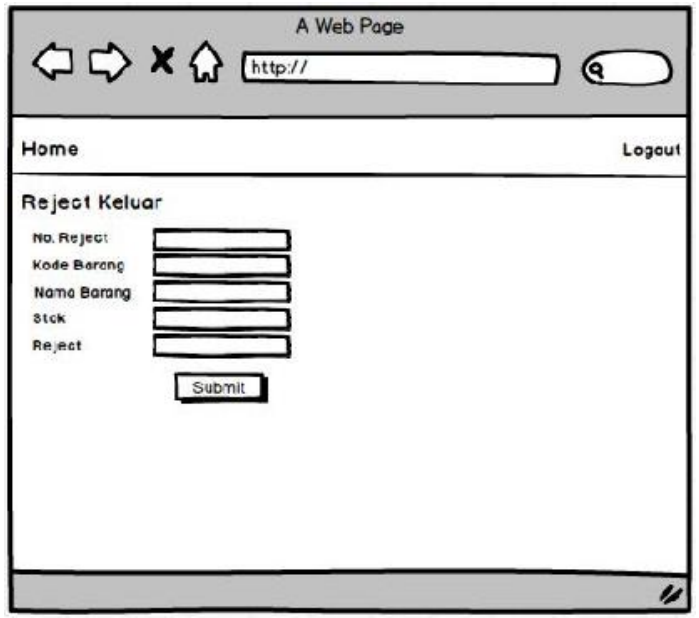

\section{Gambar 9. Racangan Reject Keluar}

Pada tampilan reject keluar, user menginputkan no reject, kode barang, nama barang, stok, dan reject.

\section{KESIMPULAN}

Berdasarkan hasil penelitian yang telah dilakukan pada sistem informasi persediaan barang pada PD. Bank Perkreditan Rakyat Kerta Raharja Kab. Tangerang, maka penulis dapat menarik kesimpulan sebagai berikut :

1. Sistem informasi persediaan barang yang berjalan pada PD. Bank Perkreditan Rakyat Kerta Raharja masih menggunakan Ms. Excel. Dimulai dari penerimaan barang dari supplier, pengeluaran barang sampai menghasilkan laporan stok barang. Meskipun berjalan dengan baik namun menimbulkan keterlambatan dalam proses pengolahan data, menyebabkan informasi yang dihasilkan sering terjadi kesalahan karena adanya perbedaan jumlah stok barang antara data yang ada dengan fisiknya dan memerlukan waktu yang lama dalam penyajian laporannya.

2. Sistem yang berjalan saat ini belum dapat memudahkan karyawan dalam memperoleh informasi, hal ini disebabkan karena masih lamanya proses pencarian dan pembuatan laporan yang akurat, sehingga proses pembuatan keputusan pun menjadi terhambat.

3. Sistem informasi persediaan ATK dirancang menggunakan metode object oriented programming dengan menggunakan tools UML (Unified Modeling Language), bahasa pemrograman PHP dan database MySQL. Sistem ini memudahkan karyawan dalam memperoleh informasi, penulis membuat rancangan sistem aplikasi yang dapat mengontrol keluar masuknya barang dan dapat mengupdate jumlah stok barang secara otomatis jika terjadi transaksi penerimaan dan pengeluaran barang 


\section{DAFTAR PUSTAKA}

[1] Safitri, Windy Lia (2014)“Analisa Sistem Informasi Manajemen Persediaan Barang Pada CV. Samat Teknik Mandiri"

[2] Susanto, Ferry (2013) berjudul "Analisa Sistem Penerimaan dan Pengeluaran Barang Berbasis Web pada PT. PANCA PRIMA EKABROTHERS”

[3] Yulianti (2011) yang berjudul "Analisa Sistem Informasi Inventory Control di PT. Panarub Industri"

[4] Novianti, Mutia Anisa (2014) yang berjudul "Perancangan Executive Information System (EIS) Penjualan Di PT. Tirta Varia Intipratama”.

[5] Yakub. 2012. Pengantar Sistem Informasi, Yogyakarta: Graha Ilmu

[6] Sutabri, Tata. 2012. Konsep Sistem Informasi. Yogyakarta: penerbit andi Sutarman. 2012. "Pengantar Teknologi Informasi". Jakarta: Bumi Aksara 